\title{
RESENHA COMO NASCEM AS DOENÇAS
}

\section{Márcia Regina Barros da Silva ${ }^{1}$ \\ Universidade de São Paulo \\ São Paulo - São Paulo - Brasil}

Resenha do livro: BENCHIMOL, Jaime Larry; JOGAS JUNIOR, Denis Guedes. Uma história das leishmanioses no novo mundo: fins do século XIX aos anos 1960. Rio de Janeiro: Editora Fino Traço e Editora Fiocruz, 2020.

"O mundo era tão recente que muitas coisas careciam de nome, e para mencioná-las se precisava apontar com o dedo."

Gabriel Garcia Márquez. Cem anos de solidão. $31^{\mathrm{a}}$ ed. Rio de Janeiro: Editora Record, s/d, p. 7.

O livro Uma história das leishmanioses no novo mundo: fins do século XIX aos anos 1960, de Jayme Larry Benchimol e Denis Guedes Jogas Júnior, publicado em 2020 pelas editoras Fino Traço, de Minas Gerais, e Fiocruz, do Rio de Janeiro, não é bem um livro, mas uma enciclopédia especializada. Desde a apresentação, Jayme Benchimol nos informa que haverá um próximo volume sobre a história de uma doença que tem características desafiadoras, seja

\footnotetext{
1 Livre-docente pela Universidade de São Paulo. Professora do Departamento de História da Faculdade de Filosofia, Letras e Ciências Humanas da Universidade de São Paulo e Coordenadora do Programa de Pós-Graduação em História Social do mesmo departamento. E-mail: marciabarrossilva@usp.br
} 
por sua amplitude e singularidades geográficas, seja pela sua epidemiologia ou pela epistemologia dos fatores que interferiram nas explicações sobre sua classificação nosológica.

A dimensão épica do presente livro não é surpresa, dada a tradição de grandes empreitadas a que Jayme Benchimol se dedica, sempre na seara da história da saúde pública e da biomedicina no Brasil, especialmente a partir do Rio de Janeiro. Em publicações anteriores já vimos pesquisas de grande fôlego, tais como a divulgação da obra de Adolpho Lutz - este em parceria com Magali Romero Sá, em vários volumes, publicados entre 2004 e 2006 ou a coordenação de publicação sobre a história da febre amarela, de 2001.

Outros trabalhos se destacam na produção do autor. O livro seminal Pereira Passos, um Haussmann tropical: a renovação urbana da cidade do Rio de Janeiro no início do século XX, de 1990; além dos livros Manguinhos do Sonho à Vida: a ciência na Belle Époque e Cobras, lagartos E outros bichos: uma história comparada dos Institutos Oswaldo Cruz e Butantan, em parceria com Luiz Antonio Teixeira, de 1993. Todos essenciais para aqueles que queiram compreender a sócio-história das doenças, da produção de conhecimentos e das tentativas de prevenção, controle ou descontrole sanitário na história do Brasil.

Esses e outros trabalhos foram realizados sob os auspícios da sua inserção na Casa de Oswaldo Cruz, unidade técnica da Fiocruz cujos objetivos principais de pesquisa e ensino fazem dela um importante espaço de produção historiográfica contemporânea.

Atualmente, a própria Fiocruz tem estado no centro das atenções, tendo em vista sua participação na produção de vacinas contra a Covid-19 no Brasil. A nova doença, de caráter pandêmico, permite visualizar ainda uma grande e trágica sequência de estratégias e tentativas para lidar com os problemas de saúde das populações, questão permanente na história brasileira. Assim como o Instituto Butantan em São Paulo, e a partir de preocupações semelhantes, a Fiocruz faz coro com outras instituições de saúde do século XXI na busca por soluções sociotécnicas que lembram às do início do século XX. Lá atrás, víamos o enfrentamento institucional da novidade da febre amarela, da varíola, do cólera, entre outras várias doenças, e hoje, com a novidade da Covid-19, vemos a persistência da preocupação com doenças imunopreveníveis, somadas às comorbidades produzidas por doenças crônicas pouco tratadas. Vemos também a constância de doenças epidêmicas que se tornam endêmicas com o passar do tempo, assim como a permanência das bárbaras e infames condições de vida da maior parte da população pobre do país.

O livro atual persegue pistas, novas e conhecidas, sobre a história das doenças designadas como leishmanioses, causadas por parasitas, os dois 
protozoários identificados em seus primórdios como Leishmania chagasi e Leishmania donovani, cujo vetor é o inseto denominado Lutzomya longipalpis, uma espécie de flebótomo - inseto que se alimenta de sangue, mosquito conhecido como birigui ou mosquito-palha. Seus hospedeiros são animais próximos do convívio humano, tais como cães, cavalos e raposas e, ao picar uma pessoa, libera o parasita na corrente sanguínea, causando doenças. A descrição da história dos dois tipos conhecidos - a leishmaniose tegumentar, ou cutânea, e a leishmaniose visceral, ou calazar - é o principal objeto de discussão do presente livro.

Para a história da saúde pública, o interesse recai especialmente na busca dos autores por traçar o enredo dos personagens envolvidos em pesquisas nos seus laboratórios ou em estudos de campo. O livro faz emergir relações de proximidade entre personagens e doenças que eram consideradas em seus primórdios tão diferentes quanto o "botão do Oriente, doença dermatológica, e calazar, que se caracterizava por febre, anemia e lesões nos órgãos internos, especialmente fígado e baço" (p. 31).

Simetricamente ao que fazem com as doenças, os autores delineiam a criação de instituições e de estratégias políticas de constituição do próprio campo da saúde pública e das transformações na medicina tropical, partindo dos debates sobre as características possivelmente autóctones das leishmanioses no continente americano, mais especialmente na América do Sul. Ao demarcar as fronteiras das doenças, saltam cientistas, médicos de diversas especialidades e instituições, que vão surgindo aos poucos: Instituto Oswaldo Cruz, Instituto Pasteur, Instituto Butantan, Instituto Bacteriológico, entre outros. Ao mesmo tempo, as ligações dos cientistas e médicos brasileiros e sul-americanos com cientistas e instituições europeias despontam de viagens, congressos e encontros, o que possibilita a Benchimol e Jogas Júnior descreverem as controvérsias científicas que uniam nacionais e estrangeiros.

Por exemplo, o debate de unicistas, discordantes sobre as origens americanas da leishmaniose, demonstrava o crescente envolvimento de diferentes instituições ao embasarem a ampliação, pelo mundo, de áreas de pesquisas e especialidades; discussão importante para os autores: "Quando começaram a aparecer trabalhos sobre a especificidade da leishmaniose americana e de seu agente causal, vozes autorizadas ergueram-se contra esta teoria" (p. 73).

Como em outras obras já citadas de Jayme Benchimol, neste trabalho também há a busca por esmiuçar o emaranhado de descrições sobre uma patologia complexa. Destaca-se o esforço por compreender os espaços brasileiros de difusão de pesquisa biomédica, acompanhando a história de pesquisadores conhecidos e de outros não tão destacados, ao mesmo tempo em 
que se salienta a amplitude das preocupações sanitárias nas Américas e a extensão das redes de contato científico entre pesquisadores de diferentes países e seus envolvimentos políticos na consecução dos projetos sanitários e científicos em debate.

São 790 páginas com diferenças na autoria dos nove capítulos: os de 1 a 4 são de autoria conjunta de Denis Guedes Jogas Júnior, que já trabalhava com o tema em pesquisa de mestrado e doutorado, e Jayme Benchimol; os de 5 a 9 são de autoria apenas de Benchimol. A divisão entre os autores indica também uma certa divisão na apreciação da história da doença. Na primeira parte, os autores analisam o surgimento da leishmaniose tegumentar por meio da identificação das primeiras aparições das lesões que viriam a caracterizar a doença em diferentes regiões do mundo, como Ásia, África e América do Sul, e notadamente em países de clima quente e úmido, como Índia e Brasil.

Os capítulos iniciais descrevem os conhecimentos acumulados nos estudos sobre as diferentes enfermidades agrupadas como leishmaniose a partir do início do século XX, que, como indicam os autores, seriam "consequência da expansão colonial europeia" (p. 29). Tal discussão não se aprofunda, mas fica evidente a importância do debate ao se acompanhar os marcos que o livro anuncia, como o início das pesquisas sobre leishmaniose com a identificação do protozoário em 1903, nos trabalhos do irlandês Charles Donovan e do escocês William Boog Leishman, médicos oficiais atuantes nos espaços do Império Britânico, especialmente na Índia. O marco final do livro gira em torno do período de publicação da obra de referência dos médicos brasileiros Samuel Barnsley Pessoa² e Mauro Pereira Barreto, de 1948, Leishmaniose Tegumentar Americana, primeiro grande inquérito epidemiológico na América do Sul.

Na segunda parte do livro sobressaem análises sobre os trabalhos de Evandro Chagas sobre a leishmaniose visceral americana, momento de ampliação das instituições, dos programas de atenção sanitária e das pesquisas sobre a doença pelo Brasil, notadamente tendo o norte e o nordeste brasileiro como campo de análise a partir dos anos 1940.

De uma doença com características benignas de manifestação cutânea para uma doença letal que atacava as vísceras, como já dito, com compro-

\footnotetext{
2 Aqui vale destacar a apontada contribuição do Centro de Apoio à Pesquisa Histórica "Sérgio Buarque de Holanda", do Departamento de História da Faculdade de Filosofia, Letras e Ciências Humanas da Universidade de São Paulo - CAPH-FFLCH/USP, cujo trabalho de catalogação e digitalização do acervo do médico Samuel B. Pessoa e de sua esposa, Jovina Rocha Álvares Pessoa, contribuiu e pode ainda contribuir como fonte documental para essa e várias outras pesquisas.
} 
metimento do baço e do fígado, caminha-se no livro por diversas outras singularidades que dependeram das diferentes regiões em que as doenças surgiam: zonas de florestas, zonas rurais, zonas tropicais, entre outras regiões de manifestações epidêmicas específicas. Na segunda parte do livro, há capítulos em que se discutem caminhos particulares, tais como epidemias ocorridas no Amazonas, em Pernambuco, na Bahia e em certas regiões do Ceará. Já em outras partes, os autores narram como a leishmaniose foi tema de diferentes especialidades médicas como dermatologia e otorrinolaringologia, até ser tematizada pela medicina tropical e pela saúde pública. A leishmaniose permitiu-se ser oportunidade para a interiorização e ampliação de instituições de assistência pelo país, assim como de certo nacionalismo e de interesse internacional no trato com as doenças tropicais.

Vê-se, como apontado na epígrafe desta resenha, que o mundo das leishmanioses era mesmo muito recente, e seus muitos nomes foram sendo constituídos à medida que a doença se expandia, sendo reconhecida, renomeada, classificada, reclassificada, e assim, retirada do meio ambiente popular - em que especialmente crianças, mas também adultos, padeciam de "úlceras de Bauru" e outras manifestações que muitas das vezes levavam à morte - para adentrar os espaços da medicina oficial.

Duas referências poderiam ser incorporadas à bibliografia do livro, como suporte para compreender a maneira de interpretar que os autores utilizam neste estudo, e que certamente são referências para Jayme Benchimol e Denis Jogas. A primeira é David Bloor, com seu livro Conhecimento e imaginário social, base da discussão da sociologia do conhecimento com o Programa Forte e com a ideia de simetria, que questiona a noção de autonomia do conhecimento e busca "capturar toda a diversidade da prática científica efetiva" (BLOOR, 2009, p. 24). A segunda é Ludwig Fleck, autor do livro Gênese e desenvolvimento de um fato científico, teórico da história e da sociologia da ciência que propõe o entendimento de todo um "sistema de referências" ao analisar, de forma semelhante aos autores, o surgimento de uma doença e de um teste laboratorial específico. Fleck interessa, pois nos aponta o óbvio: "qualquer teoria do conhecimento sem estudos históricos ou comparados permaneceria um jogo de palavras vazio, uma epistemologia imaginária" (FLECK, 2010, p. 62).

Jaime Benchimol e Denis Jogas Júnior empenharam-se exemplarmente na busca de extensa documentação, composta por variados livros, textos e artigos de época, para seguir os percursos que propiciaram as pesquisas e a criação de grupos e serviços de combate às diferentes formas de leishmaniose no Brasil. Na medida em que os programas e organizações criados perseguiam um ideal de erradicação da doença, avançava-se na institucio- 
nalização dos serviços de saúde pública no país e na América do Sul, fosse em níveis federal ou locais. Neste sentido, o livro vai apresentando o emaranhado de programas de governo, de serviços, expedições, campanhas e personagens que aparecem e desaparecem à medida que servem à causa enciclopédica de acompanhar o surgimento da leishmaniose e das pesquisas científicas mais relevantes.

Talvez aqui esteja um único ponto fraco, característico de quase toda obra de dimensões tão amplas: a grande dificuldade de concisão e, principalmente, a falta de conclusões, em cada capítulo e no próprio livro, especialmente quando se trata, como no caso, de capítulos que podem ser lidos independentes uns dos outros. Durante o percurso da exposição das suas pesquisas, os autores abrem diversos parênteses para discorrer sobre temas conexos, personagens científicos e políticos de importância, mas também os secundários, e vem daí o prolongamento da obra e a aspiração universalista que não resiste aos desvios em favor não exatamente do aprofundamento, mas da ideia de extensão, da continuidade geográfica e temporal, que açambarca muitos detalhes, mesmo que interessantes, mas também várias repetições. Contudo, a ambição totalizante, ao mesmo tempo, permite que os leitores tomem contato com um enorme conjunto de referências documentais e atualizadas referências bibliográficas, todas pertinentes e enriquecedoras.

Talvez fosse possível indicar mais uma questão, de responsabilidade da editoria e não propriamente dos autores: evidentemente, o livro deveria contar com um índice onomástico para a versão impressa, pois trata-se de uma obra com clara disposição para ser utilizada por pesquisadores das humanidades e de áreas médicas, que poderão desfrutar de mais uma valiosa e impressionante obra de referência.

\section{Referências bibliográficas}

BLOOR, David. Conhecimento e imaginário social. Tradução Marcelo do Amaral Penna-Forte. São Paulo: Editora Unesp, 2009.

FLECK, Ludwik. Gênese e desenvolvimento de um fato científico. Tradução Georg Otte e Mariana Camilo de Oliveira. Belo Horizonte: Fabrefactum, 2010.

Recebido: 17/04/2021 - Aprovado: 31/05/2021

Editores Responsáveis

Miriam Dolhnikoff e Miguel Palmeira 